\title{
Quantifying and managing food-sourced nutrient metabolism in Chinese cities
}

\author{
Tao Lin ${ }^{\mathrm{a}, \mathrm{b}}$, Jin Wang ${ }^{\mathrm{a}, \mathrm{b}}$, Xuemei Baic ${ }^{\mathrm{c}}$, Guoqin Zhang ${ }^{\mathrm{a}, \mathrm{b}}$, Xinhu Li ${ }^{\mathrm{a}, \mathrm{b}}$, Rubing Ge ${ }^{\mathrm{a}, \mathrm{b}}$, Hong \\ $\mathrm{Ye}^{\mathrm{a}, \mathrm{b}^{*}}$
}

a Key Laboratory of Urban Environment and Health, Institute of Urban Environment, Chinese Academy of Sciences, Xiamen 361021, China

${ }^{\mathrm{b}}$ Xiamen Key Laboratory of Urban Metabolism, Xiamen 361021, China

${ }^{c}$ Fenner School of Environment and Society, Australian National University, Canberra, ACT 0200, Australia

*Corresponding author: Institute of Urban Environment, Chinese Academy of Sciences, Xiamen 361021, China. Tel.:+86 5926190653

E-mail addresses: tlin@iue.ac.cn (T. Lin), jinwang@iue.ac.cn (J. Wang), Xuemei.Bai@anu.edu.au (X.M. Bai), xhli@iue.ac.cn (X.Li), gqzhang@iue.ac.cn (G.Zhang), rbge@iue.ac.cn (R.Ge), hye@iue.ac.cn (H.Ye)

Abstract: Food supply and consumption are critical for sustaining urban system functions, and are key determinants of the quantity and pathways of nutrient flow in cities. Nutrient elements from urban food consumption are becoming major pollutant sources in urban environments. Therefore, understanding flow magnitude and pathways, the role of a growing population, and changing dietary structure and technology in future nutrient metabolism are essential to understand cities as ecosystems and urban environmental management. Taking the city of Xiamen, a rapid urbanizing area of Southeast China as a case study, we simulated urban metabolism of three major food-sourced nutrient elements (carbon, nitrogen, and phosphorus or CNP) over 1991-2010 and environmental emissions. Impacts of future population growth, dietary habit change, and waste treatment improvement on various environments were forecast by scenario analysis. A sensitivity analysis was conducted to test how different waste treatment technologies affect environmental emissions from food-sourced nutrients. Our results show that the food-sourced CNP had various metabolic fluxes 
through urban systems, with carbon mostly emitted into the air and nitrogen and phosphorus mostly discharged into landfills and water. Population growth and dietary structure change will accelerate increases of nutrient emissions to the environment, whereas enhancing current waste treatment technology can just alter emissions to different environments. Based on the results, we discuss how food-sourced nutrient metabolism can be better managed, to enhance connectivity between cities and their hinterlands and maintain environmental emissions within the carrying capacity of the cities.

Keywords: urban metabolism; nutrient flows; carbon; nitrogen; phosphorus; China

\section{Introduction}

With worldwide urbanization, material and energy flows and metabolic processes within cities are increasing rapidly and becoming more complex (Chen and Chen, 2015; Kennedy et al., 2015; Lin et al., 2014; Lorenz and Lal, 2009; Bai, 2007; Grimm et al., 2008; Kaye et al., 2006; Vitousek et al., 1997). Cities are open systems and rely on material input, distribution, and output to sustain their functions. This is often referred to as urban metabolism (Bai, 2007; Kennedy et al., 2007; Wolman, 1965). These human-dominated processes extract resources from the earth's geosphere and biosphere to provide services for human life. This strengthens impacts on the environment and results in water quality degradation (Shao et al., 2006; Puckett, 1995; Gruber and Galloway, 2008), enhanced greenhouse effects (Lin et al., 2013; Kennedy et al., 2010; Popp et al., 2010), acid rain ( Schlesinger, 2009; Larssen et al., 2006), and biodiversity loss (Fujimaki et al., 2013). Urban metabolism research has attracted increased attention in the quantification of inputs, outputs, and storage of energy, water, nutrients, materials, and waste in urban areas (Conke and Ferreira, 2015; 
Kennedy et al., 2015; Lin and Grimm, 2015).

Food supply and consumption are fundamental for a city to sustain its urban population and functions. Population growth, food structure change, and environmental infrastructure development affect nutrient cycling in urban areas (Behzadian and Kapelan, 2015; Lin et al., 2014). The input of nitrogen through food consumption increased 4.5 times with fivefold growth of the population in Paris over 1801-1914 (Barles, 2007). In urban households of Minnesota, food consumption dominated (40\%, and 53\%) total household nitrogen, and phosphorus (CNP) inputs (Fissore et al., 2011). Urban population growth and nutritional transition during rapid urbanization in China has increased nutrient transfer into cities, via food supplies and accumulation as waste. Meanwhile, cultivated fields have become more dependent on chemical fertilizers, which are associated with environmental and health problems ( Gill et al., 2015; Hou et al., 2013; Lu et al., 2015; Su et al., 2015; Kearney, 2010; Wang et al., 2010). Quantitative analysis of socioeconomic and technical processes of food-sourced nutrients in cities will contribute to understanding the dynamics and trajectories of nutrient fluxes across the entire human/nature coupled ecosystem, as well as tackle environmental pollution problems caused by urbanization.

Substance flow analysis (SFA), as a transformed material flow analysis method (MFA), focuses on the flow of a given chemical element and considers all related transformation and transitions of that element ( Nakajima et al., 2011; Chen et al., 2010). SFA or MFA can quantitatively explore specific environmental pollution by tracing pollutant behavior from source to sink, and identify critical pollution processes for management. Although quantification of urban metabolism at a given time is relatively well researched, understanding of "the processes and mechanisms that shape, regulate, and govern the various flows" is even more important (Bai, 2007). However, present knowledge of 
dynamic interactions among human socioeconomic activities that determine nutrient urban influxes and fates is very limited. In our study, we try to (1) develop a quantitative model for simulating the urban metabolism of food-sourced nutrient in rapidly urbanizing Chinese cities; (2) project and compare the possible future environmental emissions from urban food-sourced CNP metabolism; (3) to examine the potential of specific technologies for controlling environmental impacts from food-sourced nutrient urban metabolism; (4) to explore sustainable food-sourced nutrient management for Chinese cities.

\section{Methods}

\subsection{Study area}

Xiamen, also known as Amoy, is a major city on the southeast coast of China. As one of the earliest Special Economic Zones in the country, Xiamen is not only one of the prominent international trading ports of China but also the principal economic mainstay of southeastern China (Lin et al., 2013). The administrative area of the city is $1,565 \mathrm{~km}^{2}$ and has a sea area of $390 \mathrm{~km}^{2}$, with a population of 3.61 million in 2011. Recent decades have seen rapid urban expansion and economic development of the city, since implementation of China's "reform and opening-up" policy in 1980. The population boomed three times from 1991 to 2010. Meanwhile, GDP increased about 30 times (Fig. 1a). With population growth and economic development, the urbanization rate increased from $39 \%$ in 1991 to $81 \%$ in 2010 , while the built area expanded rapidly from $44.9 \mathrm{~km}^{2}$ to $230 \mathrm{~km}^{2}$. Simultaneously, pollutants from urban metabolism into the environment, sometimes referred to as environmental emissions, were aggravated. For example, domestic wastewater discharged and municipal solid waste produced in Xiamen increased from 31.6 million ton and 240 thousand ton to 
399 million ton and 958 thousand ton, respectively (Fig. 1b). As an important composition of urban metabolism, total food consumption increased with population from 382 thousand ton in 1991 to 1.78 million in 2010. Although per capita food consumption hovered around $300 \mathrm{~kg}$ per year, the composition of CNP elements showed major variations, which reflected changes of food structure (Fig. 1c). As a result, the proportion of grain in food consumption of Xiamen residents declined, while the proportions of poultry meat and dairy products increased significantly, food-sourced C consumption per capita decreased, and P increased significantly.
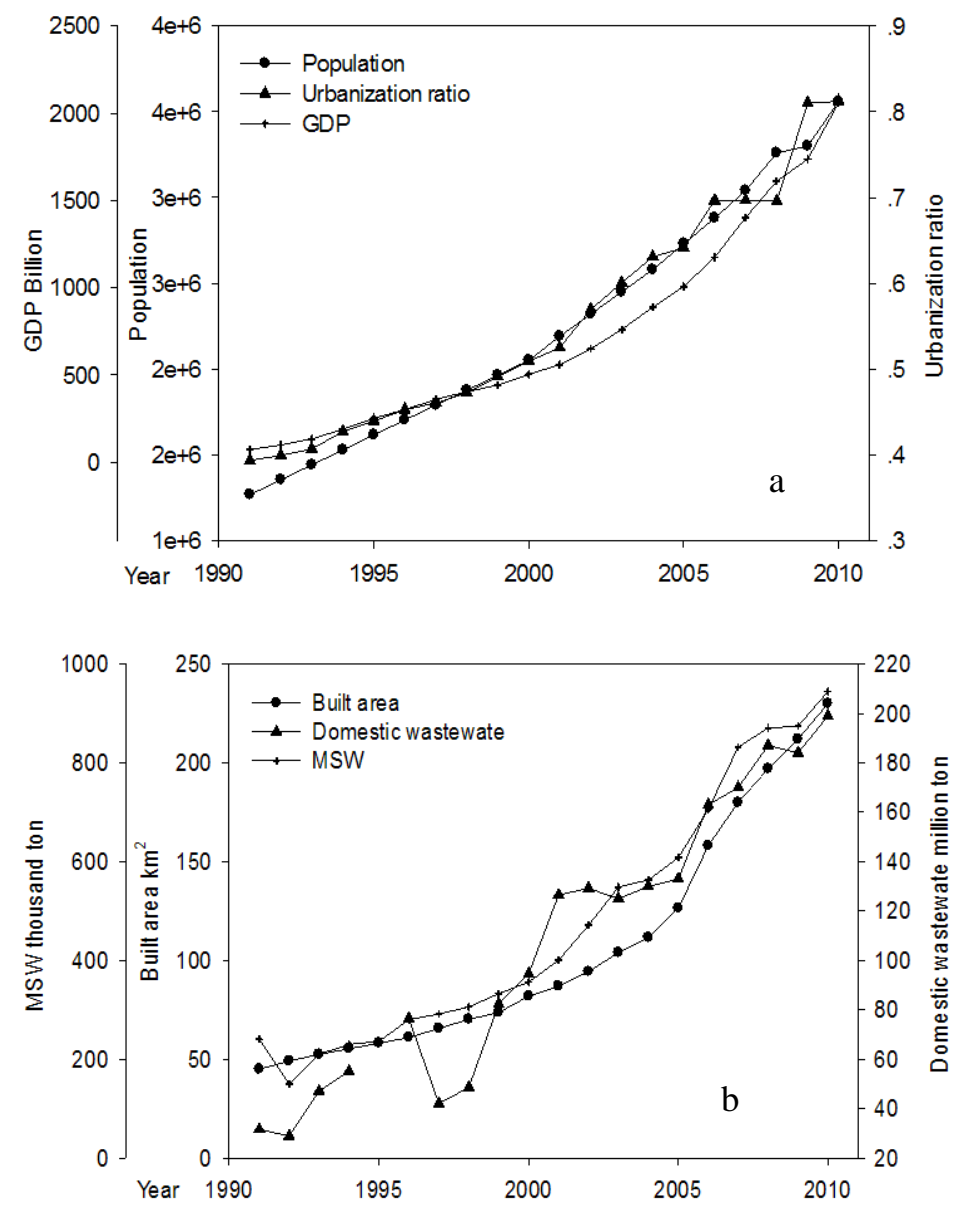


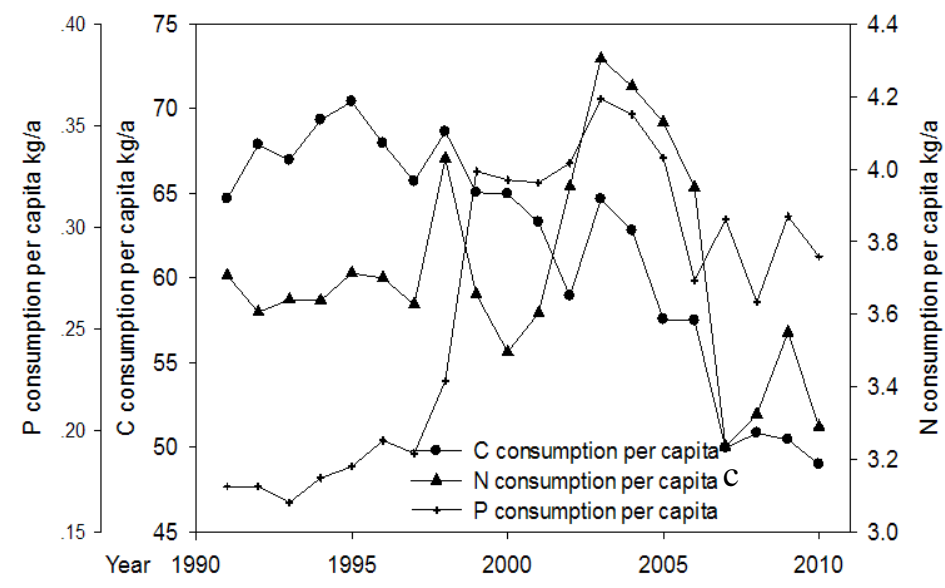

Fig. 1 Urbanization, food consumption, and environmental pollution in Xiamen during 1990-2010. Data source: Xiamen Yearbook, http://www.stats-xm.gov.cn/tjzl/tjsj/

\subsection{Analysis framework}

We developed conceptual causal chains of food-sourced CNP metabolism with its drivers and impacts, and their interaction (Fig. 2). Our analysis focused on two aspects, material (element) flow and implications for environmental management. The first part was to quantify food-sourced nutrient urban metabolism over 1991-2010, and the second part was mainly based on scenario and sensitivity analyses. Scenario analysis simulates possible future environmental emissions under variation of population growth, dietary habit change, and waste treatment technology improvement scenarios. Sensitivity analysis examines and compares the potentials of specific waste treatment technology improvements for controlling environmental impacts. All simulation and analysis were conducted using Vensim DSS software. 


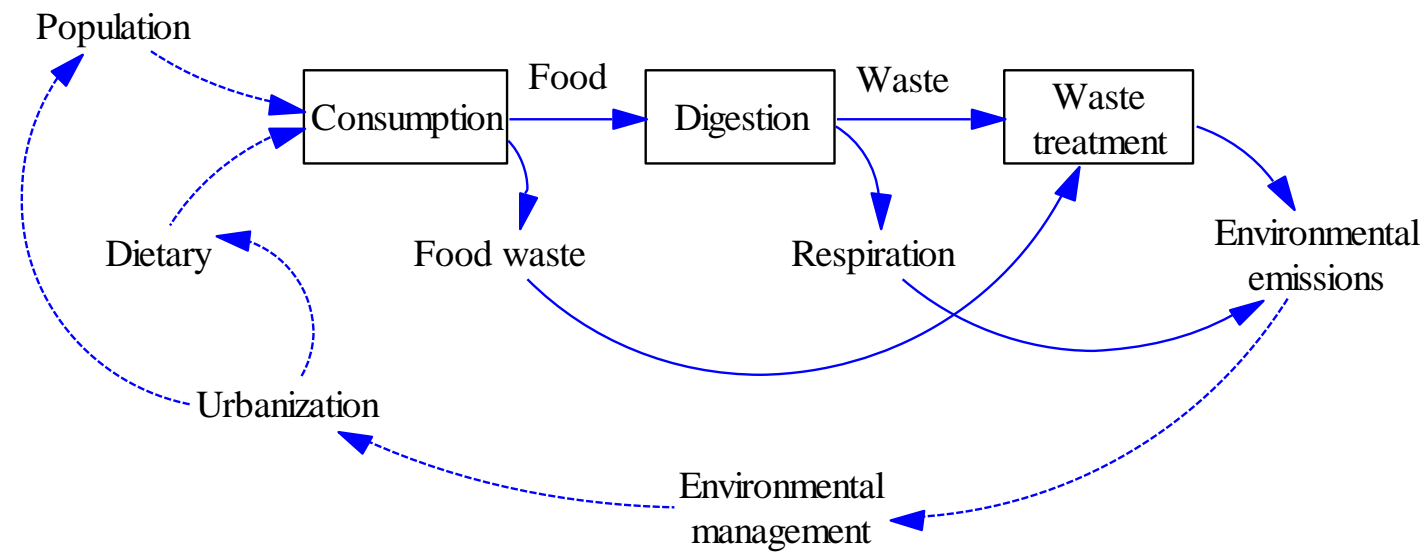

Fig. 2 Dynamic schematic of food-sourced nutrient metabolism with its drivers and impacts on the environment during urbanization. Solid lines represent material (element) flows and broken lines driving forces.

\subsection{Food-sourced CNP urban metabolism and emission simulation}

Here, we focused on dynamic flows of the three nutrient elements (CNP) through the urban system, including food consumption, human digestion, and waste treatment. Food consumption was the only nutrient input in that metabolism. The sinks had two parts. One part remained in the urban system (human bodies and landfill) and the other was released into air, water, and soil as environmental emissions. Thus, the overall food-sourced CNP urban metabolism was expressed as

$$
C N P_{\text {food }}=C N P_{\text {human }}+C N P_{\text {landfill }}+C N P_{\text {air }}+C N P_{\text {water }}+C N P_{\text {soil }}
$$

where $C N P_{\text {food }}$ represents CNP input from food consumption; $C N P_{\text {human }}$ indicates CNP stored in the human body; $C N P_{\text {air }}$, $C N P_{\text {water, }}$ and $C N P_{\text {soil }}$ represent $\mathrm{CNP}$ discharged into air, water, and soil (environmental emissions), respectively; and $C N P_{\text {landfil }}$ signifies CNP stored in landfill areas. Detailed simulation equations are in Appendix A.

\subsection{Scenario analysis}

Three scenarios were established based on possible future population growth, dietary habit change, 
and waste treatment technique improvement over 2011-2020. In all three scenarios, population growth and the urbanization ratio refer to corresponding predictions in Xiamen Economic and Social Development Twelfth Five-Year Plan and Overall Urban Plan of Xiamen City, issued by the Xiamen municipal government.

Inertial development scenario: Current dynamic interactions among population growth, food consumption pattern, and waste treatment systems remain unchanged to predict environmental emissions into air, water, and soil over 2011-2020.

Immoderate dietary structure scenario: The food consumption pattern is transformed into the high dietary energy and fat pattern in China Food Composition (Yang et al., 2002) and the average body weight increase is $10 \%$ from 2011 to 2020 . Other variables in the model remain unchanged to simulate future environmental emissions.

Waste treatment technology improvement scenario: Several waste treatment technologies that are critical in current waste treatment systems are enhanced to simulate environmental emissions from 2011 to 2020. This includes a 10\% increase in the CNP removal ratio from sewage plants, reclaimed water use increase to $40 \%$, and a $20 \%$ increase in the proportion of sludge returned to fields as fertilizer.

\subsection{Sensitivity analysis}

Seven potential technical improvements in the waste treatment system were selected. These improvements were the ratio of excreta returned to fields (RERF), ratio of wastewater treatment (RWT), ratio of reclaimed water use (RRW), ratio of sludge returned to fields, and CNP removal ratios from sewage plants (RMC, RMN, RMP) as controllable variables. Food-sourced CNP 
emissions to air, water, soil, and landfill were selected as target variables. Monte Carlo simulation, also known as multivariate sensitivity simulation in the Vensim DSS software, was done, with 200 simulations performed with a change in value of each controllable variable, from $-10 \%$ to $+10 \%$. With the change of controllable variable, target variables varied with the simulation. The mean target variable in the 200 simulations showed the sensitivities of environmental emissions to management and technical factors as in the following equation.

$$
S=\frac{1}{t} \sum_{i=1}^{t} \frac{x_{\text {tmax }}-x_{\text {tmin }}}{x_{\text {taverage }}} \times 100 \%, \quad \text { Equation } 2
$$

where $S$ represents sensitivity of the target variable to the controllable variable; $t$ is the simulation time period (10 years from 2011 to 2020); $x_{\text {tmax }}, x_{\text {tmin }}$, and $x_{\text {taverage }}$ represent the maximum, minimum, and mean of the target variable among the 200 simulation runs in a certain simulation at time $t$, respectively. A larger value of $S$ indicates greater sensitivity of the target variable to the controllable variable. 


\section{Results}

\subsection{Metabolic flux dynamics of food-sourced CNP}
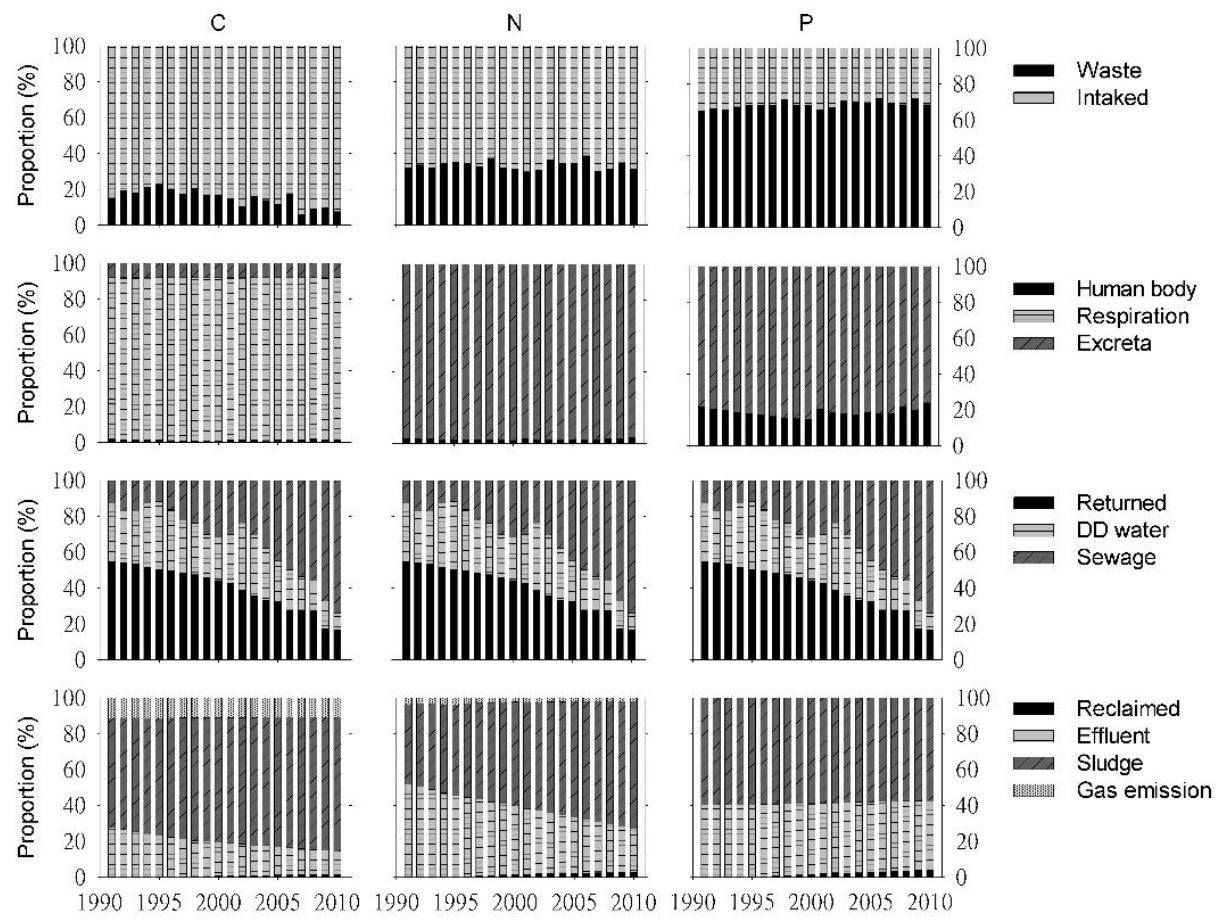

Fig. 3 Food-sourced CNP metabolic fluxes in the Xiamen urban system from 1990 to 2010. DD water signifies directly discharged wastewater.

Population growth with urbanization mainly drives food consumption and the food-sourced CNP flowing into Xiamen. Dietary habit change stimulated (such as P) or slowed (such as C) the increasing trends. The total amount of food-sourced $\mathrm{C}, \mathrm{N}$, and P increased 2.87, 3.11, and 3.55 times in 2010 relative to those ( 90.382 t, 5.864 t, and 0.478 t) in 1991. Around $20 \%$ of food-sourced C, $40 \%$ of food-sourced N, and 70\% of food-sourced P were discarded as food waste in Xiamen (Fig. 3). CNP fluctuations in food waste were mainly caused by personal dietary habits during food consumption, and there was no sign of reduction in the waste ratios over the 20 years. Human digestion is an important process that alters the fluxes of food-sourced CNP in urban ecosystems. More than $90 \%$ of intake $\mathrm{C}$ was transferred into the atmosphere as gas through respiration, while 
only $\sim 1 \%$ was accumulated in human bodies as a result of population growth, with $8 \%$ eliminated from the body as excreta. There was no gas production of $\mathrm{N}$ and $\mathrm{P}$ during human digestion. More than $97 \%$ of intake $\mathrm{N}$ was transformed into excreta, while $<3 \%$ was accumulated in human bodies. $\mathrm{P}$ was mostly accumulated in the body and only $\sim 20 \%$ was discharged. Because the human digestion process is stable, change of CNP fluxes from human food digestion strictly follows population growth.

The waste treatment system includes solid waste landfills for food waste and sludge, wastewater treatment, and excreta returned to fields. Landfill is considered a special sink for CNP from food waste and sludge. With urbanization and improvement of waste treatment infrastructure, development of the ratio of excreta collected by urban sewage plants rose from $13 \%$ to $74 \%$. Meanwhile, the ratio of excreta returned to fields and that of direct discharge decreased from 55\% and $33 \%$ in 1990 to $17 \%$ and $9 \%$ in 2010 , respectively. The ratio of $\mathrm{C}$ and $\mathrm{N}$ into the sludge increased from $68 \%$ and $45 \%$ in 1990 to $84 \%$ and $71 \%$ in 2010 , respectively. However, the ratio of P into sludge declined slightly, from $60 \%$ to $57 \%$. Reuse of reclaimed water for landscape irrigation since 1995 increased the ratio of $\mathrm{N}$ and $\mathrm{P}$ reused as reclaimed water by $3 \%$ and $4 \%$, respectively. The ratios of $\mathrm{C}$ and $\mathrm{N}$ emission into the atmosphere remained relatively stable. Meanwhile, the ratios of $\mathrm{C}$ and $\mathrm{N}$ in water through sewage plant effluent were greatly reduced, but $\mathrm{P}$ was only slightly reduced. 
3.2. Environmental emissions from food-sourced CNP urban metabolism
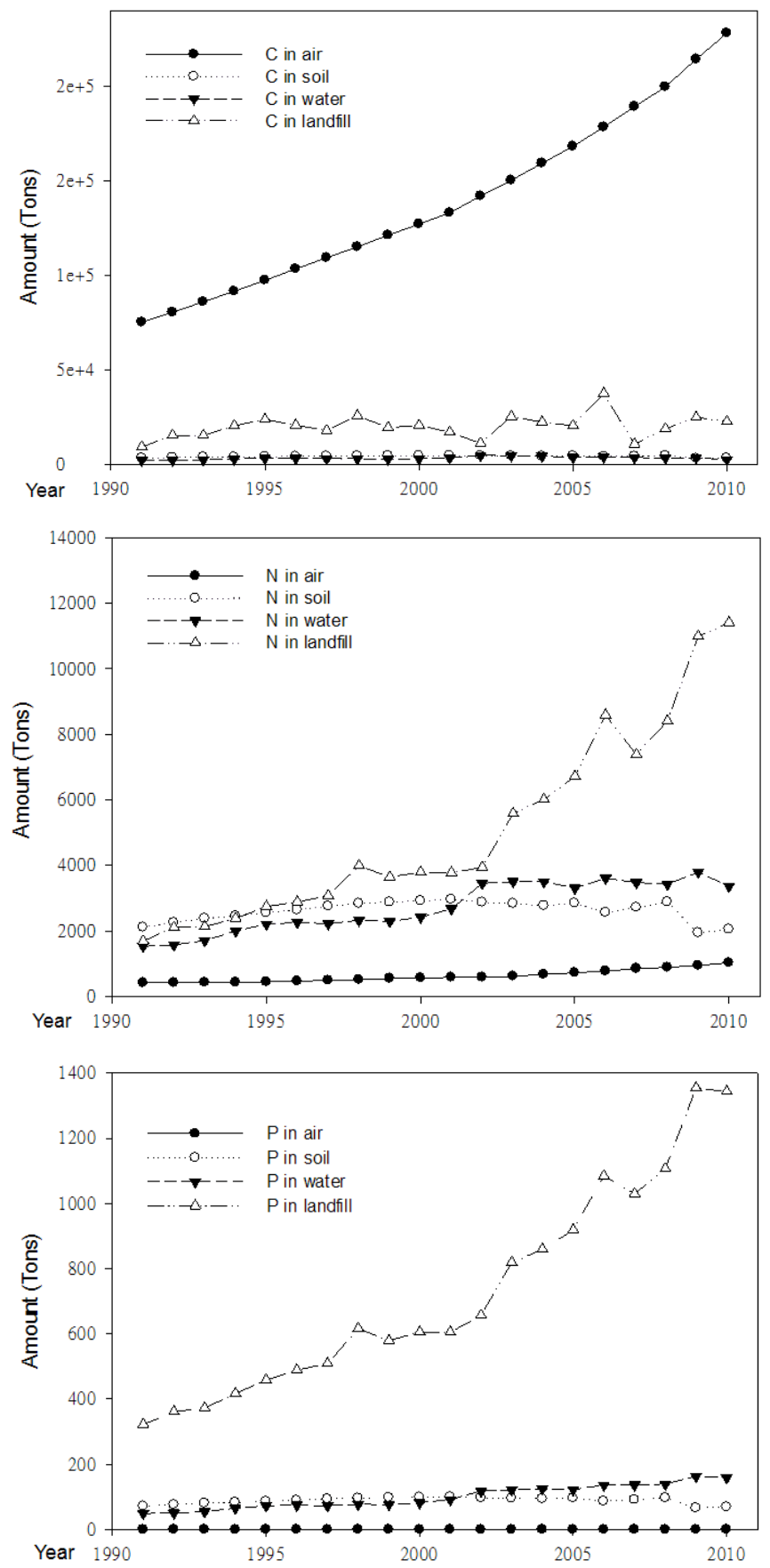

Fig. 4 Environmental emissions from food-sourced CNP urban metabolism in Xiamen from 1990 to 2010

Environmental emissions from food-sourced CNP urban metabolism increased overall, but showed various trajectories in Xiamen during 1990-2010 (Fig. 4). Food-sourced C was mainly emitted into 
the air, with the ratio increasing with population growth. The ratio of $\mathrm{C}$ into soil and water increased slightly from the mid-1990s through early 2000s with the population boom, but decreased afterward with sewage collection development. The amount of $\mathrm{C}$ into landfill was much higher than that into soil and water. Fluctuation was mainly caused by food waste production. In the early 1990s, food-sourced $\mathrm{N}$ was mainly discharged into soil, water, and landfill, with a similar ratio. With increasing food waste and excreta into waste treatment systems and sludge production growth, the amount of $\mathrm{N}$ in landfills increased rapidly while the amounts in water and soil were stable or slightly reduced. Food-sourced $\mathrm{P}$ was mainly transferred to landfills through food waste and sludge.

More than $95 \%$ of food-sourced C was emitted into the atmosphere by human respiration, whereas others came from emissions of landfill and excreta compost processes. Most food-sourced $\mathrm{N}$ in air was emitted from food waste landfills. With technical improvements of sewage plants, the ratio of sludge landfill increased from $1 \%$ to $18 \%$. Most food-sourced C into water was directly discharged, and NP was treated and discharged by sewage plant effluent. Food-sourced CNP into soil mainly came from excreta return to fields, and the ratio of reclaimed water reuse for landscapes was very small. Because all food waste and sludge were required to be treated by sanitary landfills in Xiamen, the actual load to soil was very limited. Landfills became a substantial sink for food-sourced CNP. 
3.3. Future emissions from food-sourced CNP urban metabolism

C
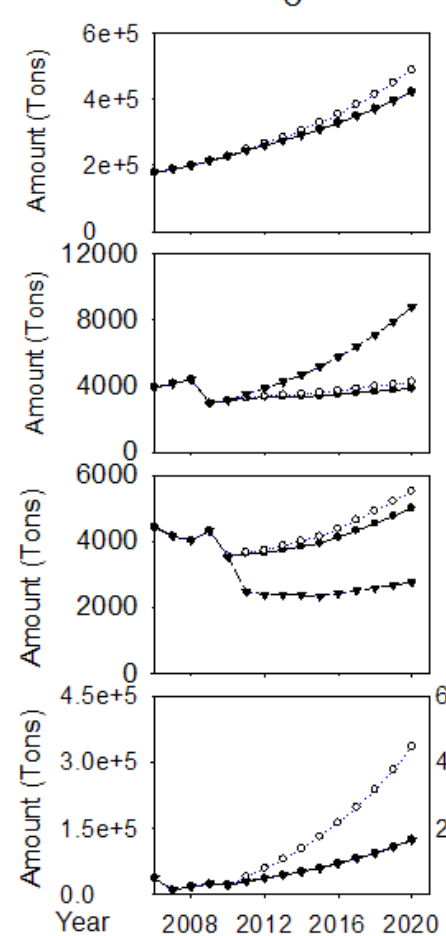

$\mathrm{N}$
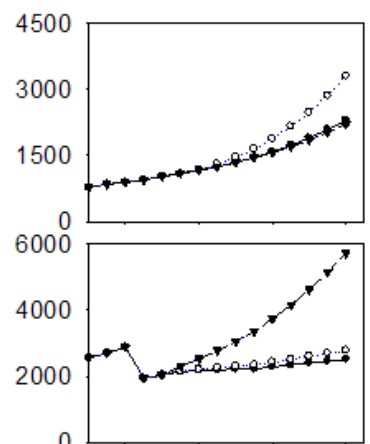

6000

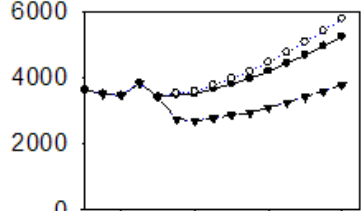

60000

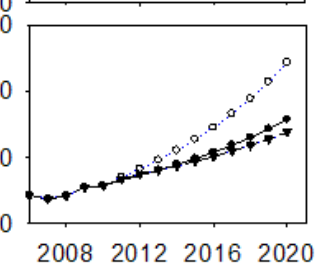

$P$
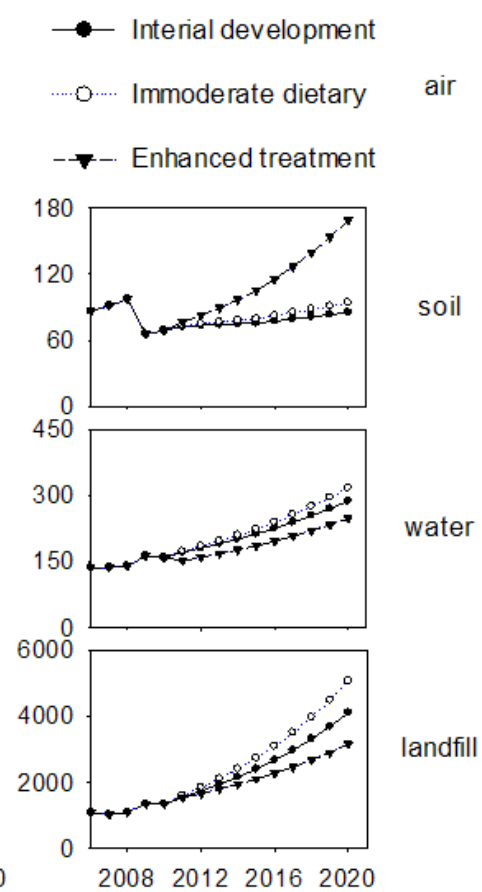

Fig. 5 Environmental emissions of food-sourced CNP urban metabolism in Xiamen in the three scenarios.

According to scenario analysis (Fig. 5), in the inertial development scenario, food-sourced CNP emissions to air, soil, water, and landfill will increase with population growth. In the immoderate dietary scenario, food-sourced CNP emissions to the environment will increase more rapidly than with the inertial development, because the former scenario will raise the total inputs of food-sourced CNP into the urban system. $\mathrm{C}$ and $\mathrm{N}$ into landfill and atmosphere will increase significantly, but CNP into water and soil will increase only slightly. This is because the immoderate dietary scenario will directly increase food waste production that will be treated in landfills, but the increase in human excreta in the wastewater treatment system will be relatively small.

The total input of food-sourced CNP in the waste treatment technology improvement scenario is the same as that in the inertial development scenario, but the metabolic fluxes and environmental 
emissions will change dramatically. Enhancing current waste treatment technologies will simply transfer more food-sourced $\mathrm{C}$ from water into soil, while amounts into air and landfills barely change. More food-sourced NP will be returned to the soil, while emissions to landfill and water will be reduced correspondingly. The food-sourced $\mathrm{P}$ into landfills will decline more significantly than $\mathrm{N}$.

However, the impact on $\mathrm{CN}$ atmospheric emissions will be relatively mall.

3.4. Sensitivity analysis of waste treatment technique improvement

Table 1 Sensitivities of environmental emissions to selected controllable variables during 2011-2020

\begin{tabular}{lllllllllllll}
\hline EL & \multicolumn{3}{c}{ Soil } & \multicolumn{3}{c}{ Landfill } & \multicolumn{3}{c}{ Air } & & \multicolumn{3}{c}{ Water } \\
CV & $\mathrm{C}$ & $\mathrm{N}$ & $\mathrm{P}$ & $\mathrm{C}$ & $\mathrm{N}$ & $\mathrm{P}$ & $\mathrm{C}$ & $\mathrm{N}$ & $\mathrm{C}$ & $\mathrm{N}$ & $\mathrm{P}$ \\
\hline $\mathrm{RERF}$ & $+19.81 \%$ & $+19.79 \%$ & $+19.75 \%$ & $0.00 \%$ & $0.00 \%$ & $0.00 \%$ & $0.00 \%$ & $0.20 \%$ & $-16.98 \%$ & $-11.08 \%$ & $-7.03 \%$ \\
$\mathrm{RWT}$ & $0.09 \%$ & $0.10 \%$ & $0.15 \%$ & $0.00 \%$ & $+11.23 \%$ & $+2.66 \%$ & $0.01 \%$ & $+3.84 \%$ & $-89.44 \%$ & $-51.17 \%$ & $-25.03 \%$ \\
$\mathrm{RRW}$ & $0.09 \%$ & $0.10 \%$ & $0.15 \%$ & $0.00 \%$ & $0.00 \%$ & $0.00 \%$ & $0.00 \%$ & $0.00 \%$ & $-1.92 \%$ & $-2.31 \%$ & $-2.58 \%$ \\
$\mathrm{RSRF}$ & $+2.33 \%$ & $+2.31 \%$ & $+1.85 \%$ & $0.13 \%$ & $0.29 \%$ & $0.07 \%$ & $0.00 \%$ & $0.00 \%$ & $0.00 \%$ & $0.00 \%$ & $0.00 \%$ \\
$\mathrm{RMC}$ & $0.56 \%$ & $0.00 \%$ & $0.00 \%$ & $0.00 \%$ & $0.00 \%$ & $0.00 \%$ & $0.00 \%$ & $0.00 \%$ & $-78.72 \%$ & $0.00 \%$ & $0.00 \%$ \\
$\mathrm{RMN}$ & $0.00 \%$ & $0.35 \%$ & $0.00 \%$ & $0.00 \%$ & $+11.23 \%$ & $0.00 \%$ & $0.00 \%$ & $+2.86 \%$ & $0.00 \%$ & $-50.45 \%$ & $0.00 \%$ \\
$\mathrm{RMP}$ & $0.00 \%$ & $0.00 \%$ & $0.22 \%$ & $0.00 \%$ & $0.00 \%$ & $+2.66 \%$ & $0.00 \%$ & $0.00 \%$ & $0.00 \%$ & $0.00 \%$ & $-24.78 \%$ \\
\hline
\end{tabular}

${ }^{a}$ EL and CV represent environmental emissions and controllable variables, respectively. RERF, RWT, RRW, and RSRF represent ratios of excreta returned to field, wastewater treatment, reclaimed water use, and sludge returned to field, respectively. RMC, RMN, and RMP designate CNP removal ratios of sewage plants, respectively. + and represent positive and negative relationships between the target and controllable variables.

According to the sensitivity analysis (Table 1), environmental emissions from the food-sourced CNP urban metabolism technologies respond differently to the seven waste treatment technologies. No single technology can deal with all three elements' emissions to all types of environment. RERF has the broadest capacity to control CNP into soil and water, whereas RMC can only affect $\mathrm{C}$ into water. A large sensitivity value indicates strong capacity of the technique in controlling the target environmental emissions from food-sourced CNP urban metabolism. For example, RWT has the 
strongest capacity to control NP into landfill and CNP into water.

Obviously, the technologies responding to food-sourced CNP into water, air, soil, and landfill have varying sensitivities. Most of the technologies except the ratio of sludge returned to the field will affect the food-sourced CNP into water. However, no technique could affect the food-sourced C into air and landfill. The relationship between the seven waste treatment technologies and food-sourced CNP emissions to the environments appears complex. RERF will increase CNP emission into soil and reduce the emission into water. RWT will amplify NP into landfill and decrease CNP into water. It is interesting that with improvements in all the waste treatment technologies, food-sourced nutrients will be more likely transferred from water to other environments.

\section{Discussion}

\subsection{Managing food-sourced nutrient urban metabolism in China}

Population growth is the determining driver for food-sourced nutrient urban metabolism and reduction, and our scenario analysis proved that slowing population growth would directly decrease the input of nutrients into the city and resulting emission to the environment. However, China is just entering a rapid urbanization stage. The recently issued National New-type Urbanization Plan sets targets for the country's urban population fraction to rise by $1 \%$ annually, to reach $60 \%$ by 2020 (Bai et al., 2014). Under such rapid urbanization, better understanding of the environmental impacts of food supply and consumption would contribute to improved management of cities in the long run. Dietary habit of urban residents in China is another important factor for controlling food-sourced CNP metabolism, both input and subsequent output (Lin et al., 2015; Lin et al., 2014; Guilin et al.,

2012). This has two aspects. The first is maintaining a healthy diet and avoiding excess nutrient 
intake, and the other is reducing waste production during food processing and consumption. The traditional grain-based diet in China is rapidly changing, with an increasing intake of animal-derived foods (Hou et al., 2013; Liu et al., 2014; Shimokawa, 2015). This transition may be a result of differences in sociodemographic factors and other consumer characteristics, which apparently will not change in the near future (Kearney, 2010). Li et al. (2012) found that the impact of dietary P on urban environmental systems in Chinese cities, follows the environmental Kuznets curve. However, a reduction in food waste can greatly neutralize the impact of a high-nutrient diet on the environment. It is estimated that nearly one third of all food is lost during consumption globally (FAO, 2013). In our study, $440 \%$ of food-sourced $\mathrm{N}$ and $70 \%$ of food-sourced $\mathrm{P}$ were discarded as food waste in Xiamen. Therefore, a reduction in food waste will be the most effective measure in Chinese cities in the near future, and a slight change in food consumption behavior can have significant impacts. Waste treatment system improvement is always considered a major solution to urban environment pollution. However, our study found that the current urban waste treatment system only alters emission directions of food-sourced nutrients to the environment. In other words, current treatment systems in China simply transfer the pollution from the city to other locations (rural or nature). Boundary definition is important for urban metabolism analysis (Chen, et al., 2015; Chen and Chen, 2012). Our study focused on the food sourced elements flows and emissions stemmed from food consumption within the city and the following treatment. From a life cycle assessment perspective, the production and supply sectors related to the food consumption should be considered and it will discussed in the following section. 
4.2. Towards a sustainable food-sourced nutrient urban metabolism

With urbanization, urban waste treatment systems are increasingly important in managing food-sourced nutrient metabolism. Various management options and technological innovations in waste treatment can alter the output end of urban nutrient metabolism. Our sensitivity analysis revealed the potential of current waste treatment techniques to deal with the various environmental impacts from food-sourced nutrient urban metabolism. It is obvious that current urban waste treatment in Xiamen has three weaknesses in managing nutrient waste: (1) Landfill became a major sink for nutrient waste, becoming an endpoint and breaking the connection between urban nutrient metabolism and its integration with natural biogeochemical cycling. (2) Although water pollution caused by $\mathrm{P}$ or $\mathrm{N}$ is one of the major issues caused by nutrient metabolism in cities, too much emphasis on transferring wasted nutrients from water to other environments (Table 1) ignores the contamination of air or soil in the process. (3) Capacities of waste treatments for different nutrient elements vary. For example, the sewage treatment technique fails in reclaiming $\mathrm{P}$ as efficiently as $\mathrm{C}$ and $\mathrm{N}$ caused the coastal eutrophication problem in Xiamen. Controlling emissions to the environment by food-sourced nutrient urban metabolism requires comprehensive and systemic organization of different waste treatment technologies. However, urban metabolic nutrients cannot be absorbed substantially by urban systems themselves. Food-caused environment pollution in China is mainly induced by interrupting nutrient cycling between food production (rural area) and consumption (urban area) ( Lin et al., 2014; Ma et al., 2014; Hou et al., 2013; Liu et al., 2008). Food-sourced nutrients can accumulate in specific areas (such as landfill sites or water bodies) of cities, which increases environmental pollution and ecological risk or transfers them to neighboring 
areas. From a life cycle perspective, sustainable management of the nutrients in urban metabolism should aim to reconnect the broken nutrient cycle by connecting cities with their ecological hinterlands (food supply system), while ensuring that local emissions (leaks) do not exceed the environmental carrying capacity of urban ecosystems (Chen and Chen, 2015; Singh and Bakshi, 2013). The complex relationships among driving forces, nutrient flows, and technologies are simplified in Fig. 6.

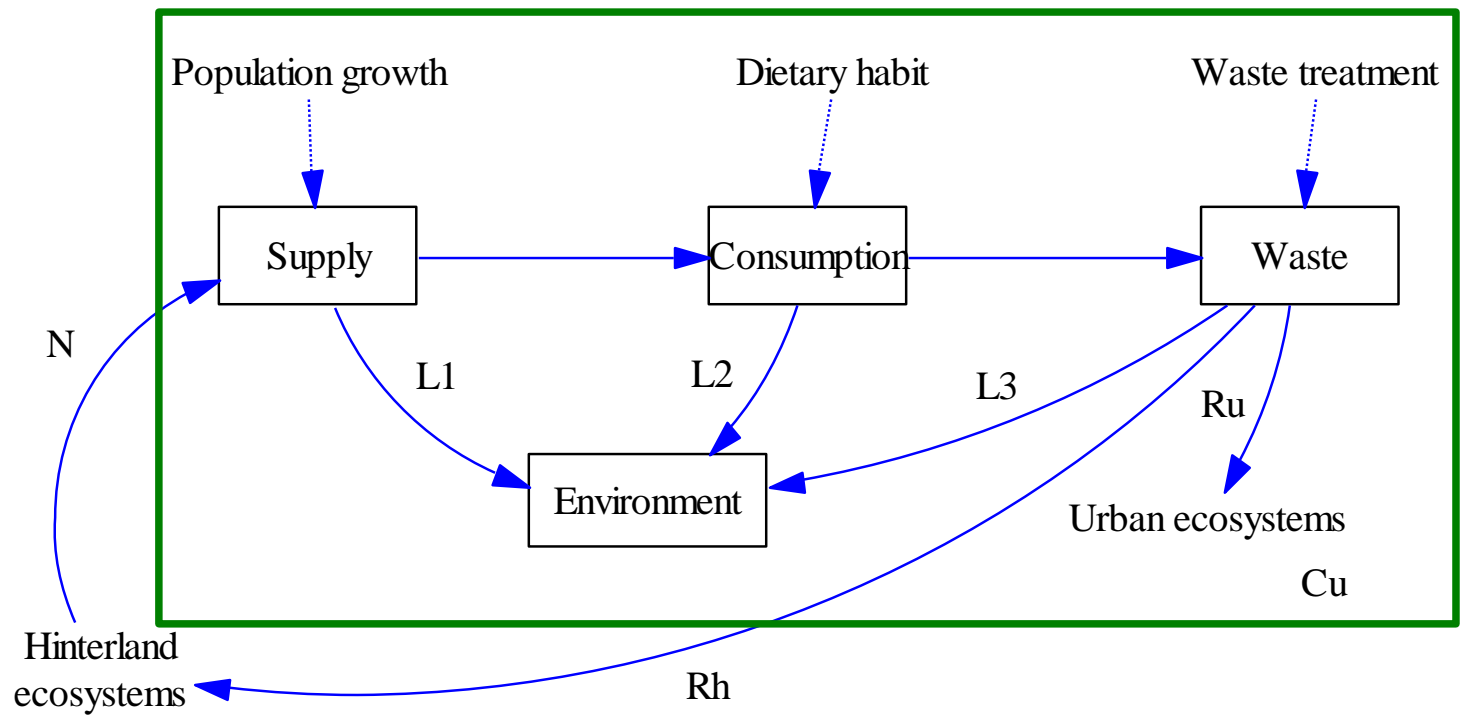

Fig. 6 Conceptual framework for sustainable management of urban nutrient metabolism In the figure, $R$ represents the maximum amount of urban metabolic nutrient recycled into the urban ecosystem $R u$ and into the hinterland ecosystem $R h . N$ represents the food-sourced nutrient supply for the city. $\sum L$ stands for the total leaked nutrient from all urban metabolic stages, such as $L_{1}, L_{2}$, and $L_{3} . C u$ represents the environmental carrying capacity of an urban ecosystem. The quantitative relationship among these variables can be expressed by $N=\sum L+R, R=R h+R u$, and $R u+\sum L<C u$. In the figure, solid lines represent material (element) flows, and broken lines driving forces.

\section{Conclusions}

The rapidly growing urban population in Chinese cities has placed great demands on dietary improvement, with dietary structure changing significantly during the last few decades. Meanwhile, 
discharged nutrients from food waste and human excreta exerted great pressure on the urban environment with population growth and food consumption pattern changes. Our study developed a quantitative model for simulating the urban metabolism of food-sourced nutrient emphasizing the three element (CNP) flows and their implications for environmental management. The case study of Xiamen City show that the food-sourced CNP had various metabolic fluxes through urban systems, with carbon mostly emitted into the air and nitrogen and phosphorus mostly discharged into landfills and water. Scenario analysis prove that population growth, dietary habit change, and waste treatment improvement are critical for managing food-sourced nutrient metabolism in Chinese cities. Given that control of the growing population or reducing nutrient intake is unlikely at least in the short run, improving urban waste treatment systems can be a principal strategy to deal with urban nutrient pollution for a single city. However, the sensitive analysis found that the current urban waste treatment technologies are essentially transferring the output end of nutrient metabolism to different environments, and exacerbating the disconnection between cities and their ecological hinterlands. Such a limitation of technical approaches to managing urban metabolism must be recognized. From sustainable management perspective, a comprehensive systems approach that reconnects urban nutrient metabolism to broader biogeochemical cycles is essential for Chinese cities.

\section{Competing financial interests}

No conflicts of interest for any author.

\section{Acknowledgments}

The authors are grateful for the support of the National Science Foundation of China (41201598, 
41371540), the China High-Resolution Earth Observation System, the Chinese Academy of Sciences (KZZD-EW-16, KFJ-EW-STS-088), and the Xiamen and Ningbo Municipal Bureau of Science and Technology (35O2Z20130037, 201401A1007007). .

\section{References}

Bai, X. Industrial ecology and the global impacts of cities. J IND ECOL. 11:1-6; 2007

Bai, X.; Shi, P.; Liu, Y. Realizing China's urban dream. NATURE. 509:158-160; 2014

Barles, S. Feeding the city: Food consumption and flow of nitrogen, Paris, 1801-1914. SCI TOTAL ENVIRON. 375:48-58; 2007

Behzadian, K.; Kapelan, Z. Advantages of integrated and sustainability based assessment for metabolism based strategic planning of urban water systems. SCI TOTAL ENVIRON. 527:220-231; 2015

Chen. B.; Yang, J. X; Shi, Y.; Ouyang, Z. Y. Framework and indicator system of urban material flow analysis. ACTA ECOLOGIA SINICA, 30: 6289-6296; 2010

Chen, B.; Chen, S.Q. Urban metabolism and nexus. ECOL INFORM. 26: 1-2; 2015

Chen, $\mathrm{S}$ et al. Non-zero-sum relationships in mitigating urban carbon emissions: a dynamic network simulation. ENVIRON SCI TECHNOL. 49: 11594-11603; 2015

Chen, S.Q.; Chen, B. Network environ perspective for urban metabolism and carbon emissions: A case study of Vienna, Austria. ENVIRON SCI TECHNOL. 46: 4498-4506; 2012Conke, L.S.; Ferreira, T.L. Urban metabolism: Measuring the city's contribution to sustainable development. ENVIRON POLLUT. 202:146-152; 2015

Cui, S.; Shi, Y.; Groffman, P.M.; Schlesinger, W.H.; Zhu, Y. Centennial-scale analysis of the creation and fate of reactive nitrogen in China (1910-2010). P NATL ACAD SCI USA. 110:2052-2057; 2013

Fissore, C.; Baker, L.A.; Hobbie, S.E.; King, J.Y.; McFadden, J.P.; Nelson, K.C., et al., Carbon, nitrogen, and phosphorus fluxes in household ecosystems in the Minneapolis-Saint Paul, Minnesota, urban region. ECOL APPL. 21:619-639; 2011

FAO, 2013. Food Wastage Footprint: Impacts on Natural Resources.

Fujimaki, R.; Sakai, A.; Kaneko, N. Ecological risks in anthropogenic disturbance of nitrogen cycles in natural terrestrial ecosystems. ECOL RES. 24:955-964; 2009Gill, M.; Feliciano, D.; Macdiarmid, J.; Smith, P. The environmental impact of nutrition transition in three case study countries. FOOD SECUR. 7:493-504; 2015

Grimm, N.B.; Faeth, S.H.; Golubiewski, N.E.; Redman, C.L.; Wu, J.; Bai, X., et al., Global change and the ecology of cities. SCIENCE. 319:756-760; 2008

Gruber, N.; Galloway, J.N. An Earth-system perspective of the global nitrogen cycle. NATURE. 451:293-296; 2008

Hou, Y.; Ma, L.; Gao, Z.L.; Wang, F.H.; Sims, J.T.; Ma, W.Q., et al., The Driving Forces for Nitrogen and Phosphorus Flows in the Food Chain of China, 1980 to 2010. J ENVIRON QUAL. 42:962-971; 2013 Kaye, J.P.; Groffman, P.M.; Grimm, N.B.; Baker, L.A.; Pouyat, R.V. A distinct urban biogeochemistry? TRENDS ECOL EVOL. 21:192-199; 2006 
Kearney, J. Food consumption trends and drivers. PHILOS T R SOC B. 365:2793-2807; 2010

Kennedy, C.; Cuddihy, J.; Engel-Yan, J. The changing metabolism of cities. J IND ECOL. 11:43-59; 2007

Kennedy, C.A.; Stewart, I.; Facchini, A.; Cersosimo, I.; Mele, R.; Chen, B., et al., Energy and material flows of megacities. P NATL ACAD SCI USA. 112:5985-5990; 2015

Larssen, T.; Lydersen, E.; Tang, D.G.; He, Y.; Gao, J.X.; Liu, H.Y., et al., Acid rain in China. ENVIRON SCI TECHNOL. 40:418-425; 2006

Li, G.; Bai, X.; Yu, S.; Zhang, H.; Zhu, Y. Urban Phosphorus Metabolism through Food Consumption the Case of China. J IND ECOL. 16:588-599; 2012

Lin, J.; Hu, Y.; Cui, S.; Kang, J.; Xu, L. Carbon footprints of food production in China (1979-2009). J CLEAN PROD. 90:97-103; 2015

Lin, T.; Gibson, V.; Cui, S.; Yu, C.; Chen, S.; Ye, Z., et al., Managing urban nutrient biogeochemistry for sustainable urbanization. ENVIRON POLLUT. 192:244-250; 2014

Lin, T.; Grimm, N.B. Comparative study of urban ecology development in the US and China: Opportunity and Challenge. URBAN ECOSYST. 18:599-611; 2015

Lin, T.; Yu, Y.; Bai, X.; Feng, L.; Wang, J. Greenhouse Gas Emissions Accounting of Urban Residential Consumption: A Household Survey Based Approach. PLOS ONE. 8; 2013

Liu, C.; Wang, Q.; Mizuochi, M.; Wang, K.; Lin, Y. Human behavioral impact on nitrogen flow - A case study of the rural areas of the middle and lower reaches of the Changjiang River, China. AGR ECOSYST ENVIRON. 125:84-92; 2008

Liu, C.; Zou, C.; Wang, Q.; Hayashi, Y.; Yasunari, T. Impact assessment of human diet changes with rapid urbanization on regional nitrogen and phosphorus flows-a case study of the megacity Shanghai. ENVIRON SCI POLLUT R. 21:1905-1914; 2014

Lorenz, K.; Lal, R. Biogeochemical C and N cycles in urban soils. ENVIRON INT. 35:1-8; 2009

Lu, Y.; Song, S.; Wang, R.; Liu, Z.; Meng, J.; Sweetman, A.J., et al., Impacts of soil and water pollution on food safety and health risks in China. ENVIRON INT. 77:5-15; 2015

Ma, L.; Guo, J.; Velthof, G.L.; Li, Y.; Chen, Q.; Ma, W., et al., Impacts of urban expansion on nitrogen and phosphorus flows in the food system of Beijing from 1978 to 2008. GLOBAL ENVIRON CHANG. 28:192-204; 2014

Nakajima, K.; Nansai, K.; Matsubae, K.; Kondo, Y.; Kagawa, S.; Inaba, R., et al., Identifying the Substance Flow of Metals Embedded in Japanese International Trade by Use of Waste Input-Output Material Flow Analysis (WIO-MFA) Model. ISIJ INT. 51:1934-1939; 2011

Puckett, 1.j. Identifying the major sources of nutrient water-pollution. ENVIRON SCI TECHNOL. 29:A408-A414; 1995

Shao, M.; Tang, X.; Zhang, Y.; Li, W. City clusters in China: air and surface water pollution. FRONT ECOL ENVIRON. 4:353-361; 2006

Shimokawa, S. Sustainable meat consumption in China. J INTEGR AGR. 14:1023-1032; 2015

Singh, S.; Bakshi, B. R. Accounting for the Biogeochemical Cycle of Nitrogen in Input-Output Life Cycle Assessment. ENVIRON SCI TECHNOL. 47: 9388-9396; 2013

Su, C.; Jia, X.; Wang, Z.; Wang, H.; Zhang, B. Trends in dietary cholesterol intake among Chinese adults: a longitudinal study from the China Health and Nutrition Survey, 1991-2011. BMJ OPEN. 5; 2015

Vitousek, P.M.; Mooney, H.A.; Lubchenco, J.; Melillo, J.M. Human domination of Earth's ecosystems. SCIENCE. 277:494-499; 1997

Wang, J.; Xu, Z.; Peng X. Change Trend of Chinese Urban Residents Food-nitrogen Consumption. J 
ANHUI AGR SCI 38: 10332-10334; 2010.

Schlesinger, W.H. On the fate of anthropogenic nitrogen. P NATL ACAD SCI USA. 106:203-208; 2009 Wolman, A. Metabolism of cities. SCIENT AMERICAN 213, 179-190; 1965.

Yang, Y. X.; Wang, G. Y.; Pan, X. C. China food composition [M]. Peking University Medical Press, Beijing, 2002. 